

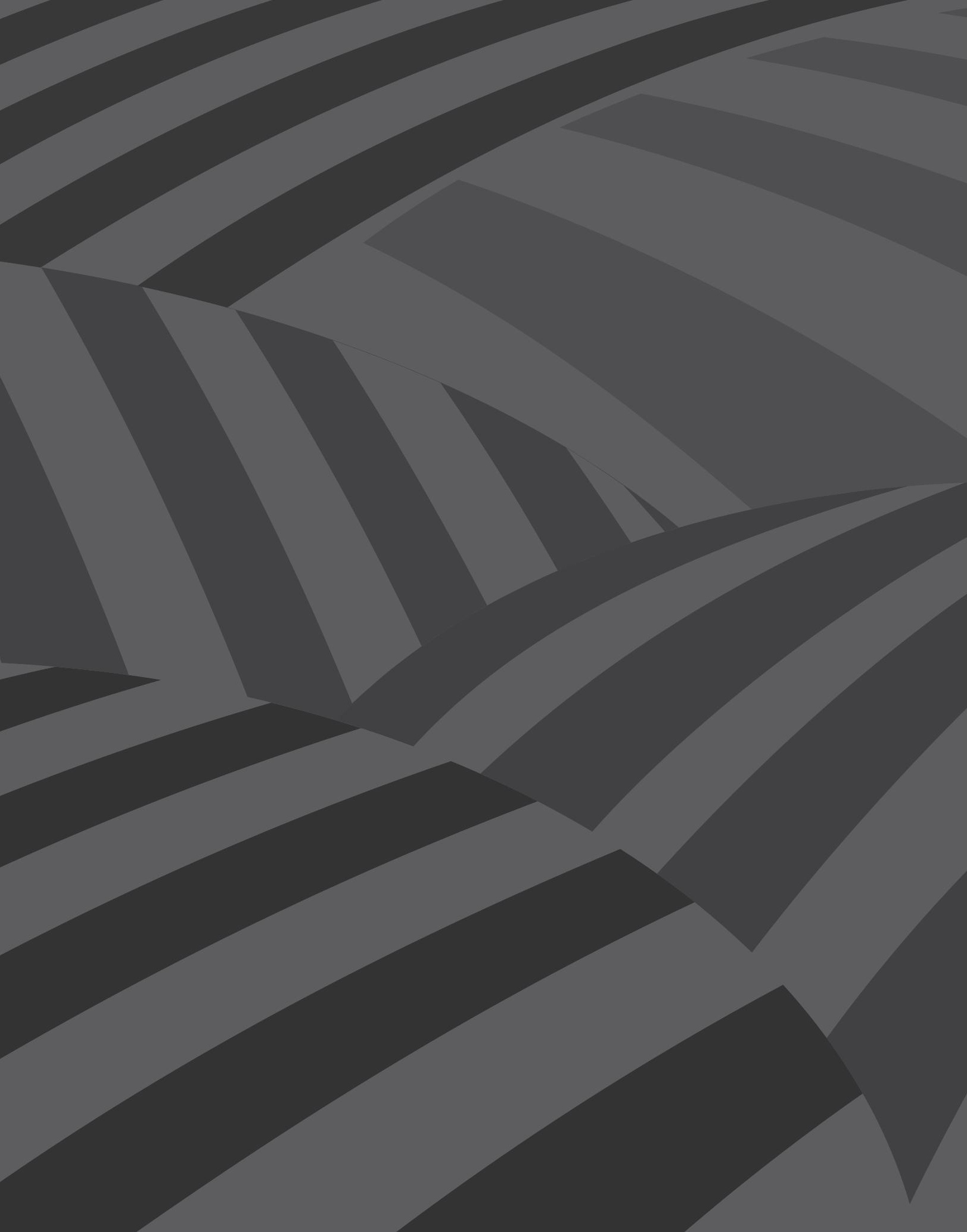




\title{
Memoria y apropiación del pasado: una interpretación de la lucha en Oaxaca, México
}

\author{
Por Eduardo Carlos Bautista Martínez*, Iván Israel Juárez López**
}

\begin{abstract}
Resumen: La dificultad teórico-metodológica del artículo se sintetiza en las siguientes interrogantes: ¿Cómo abordar luchas que tienen expresiones en la memoria colectiva e imaginarios populares? ¿Es posible la comprensión de estas luchas bajo los marcos analíticos de la acción colectiva y los movimientos sociales? ¿En qué términos puede justificarse esta relación? Y, si no es así, ¿qué otras propuestas teórico-metodológicas resultan útiles para comprender las luchas que buscan recuperar y apropiarse del pasado? Nuestro supuesto es que las luchas con expresiones en los imaginarios populares y la memoria colectiva están negadas en los rasgos visibles e inmediatos de la acción colectiva y los movimientos sociales que responden más bien a programas racionales y jerárquicos. El objetivo de este artículo es desarrollar una propuesta teórico-metodológica que dé lugar a la comprensión de aquellas luchas ancladas en la vida local y que también nos permita recuperar los rasgos y cualidades negados en los marcos analíticos predominantes. Para sustentar estos argumentos, se retoma la experiencia de activistas que irrumpieron en los acontecimientos en Oaxaca, entidad del sureste mexicano, a partir del año 2006.
\end{abstract}

Palabras clave: sociología, movimientos sociales, memoria, lucha, antagonismo, Oaxaca, México.

\section{Memory and Appropriation of the Past: An Interpretation of the Struggle in Oaxaca, Mexico}

Abstract: The theoretical-methodological difficulty of the article is summarized in the following questions: How to address the struggles that have expressions in collective memory and

* Doctor en Ciencias Sociales por la Universidad Autónoma Metropolitana. ProfesorInvestigador adscrito al Instituto de Investigaciones Sociológicas de la Universidad Autónoma «Benito Juárez» de Oaxaca. Distinción de Investigador Nacional Nivel I dentro del Sistema Nacional de Investigadores del Consejo Nacional de Ciencia y Tecnología. Correo electrónico: ecbm00@hotmail.com

** Maestrante en Sociología por el Instituto de Investigaciones Sociológicas de la Universidad Autónoma «Benito Juárez» de Oaxaca, México. Programa Nacional de Posgrados de Calidad (PNPC) del Consejo Nacional de Ciencia y Tecnología. Correo electrónico: ivaniisuabjo@gmail.com 
popular imaginary? Is it possible to understand these struggles under the analytical frameworks of collective action and social movements? In what terms can this relationship be justified? And if not, what other theoretical-methodological proposals are useful to understand the struggles that seek to recover and appropriate the past? Our assumption is that struggles with expressions in the collective memory and the popular imaginary are denied in the visible and immediate characteristics of collective action and social movements that respond rather to rational and hierarchical programs. Therefore, the objective of this article is to develop a theoretical-methodological proposal that allows the understanding of these struggles anchored in local life and at the same time allows recovering the aspects that have been denied by the dominant analytical frameworks. To support these arguments, let's recover the experience of the activists who broke into the events that took place in 2006 in Oaxaca, an entity located in southern Mexico.

Keywords: sociology, social movements, memory, struggle, antagonism, Oaxaca, Mexico.

Cómo citar este artículo: Bautista Martínez, Eduardo Carlos y Juárez López, Iván Israel (2019). Memoria y apropiación del pasado: una interpretación de la lucha en Oaxaca, México. Revista Controversia, 213, 375-411.

Fecha de recepción: 29 de marzo de 2019

Fecha de aprobación: 10 de julio de 2019

La modernidad intenta definirse en contra del mito. El mito parece el pasado atávico de la humanidad, la razón moderna como la razón que sustituye los mitos. El mito parece ser lo primitivo, la razón ilumina y deja atrás el mito. La modernidad parece desmitización y desmagización (...) Sin embargo, la modernidad piensa en mitos tanto como cualquier sociedad anterior.

Hinkelammert, 2007, p. 41.

No hay hombre que viva sin soñar despierto;

de lo que se trata es de conocer cada vez más estos sueños, a fin de mantenerlos así dirigidos a su diana eficazmente, certeramente. ¡Que los sueños soñados despierto se hagan más intensos! Bloch, 2007, p. 2. 


\section{Introducción}

$\mathrm{L}$

a evidencia empírica muestra que los marcos de interpretación de la acción colectiva y los movimientos sociales ya no son pertinentes para comprender las expresiones de lucha que irrumpen, con distintas motivaciones, en escenarios locales con características efímeras y dispersas. Ya no parece aceptable la clasificación «objetiva» y jerárquica de las luchas por su menor o mayor importancia, así como tampoco sus abordajes pragmáticos de victorias o fracasos. Incluso, el término movimiento social que pretendía ser la ampliación renovada de la comprensión de las luchas y de sus potencialidades transformativas, señala Gutiérrez (2015), ha colapsado y se ha convertido en un concepto cerrado que oculta u opaca otras expresiones colectivas que son reducidas al simple registro anecdótico por quienes buscan, precisamente, el estallido de grandes conflagraciones de confrotaciones abiertas.

La consecuencia inmediata es evidente en el poco trabajo documental que existe acerca de luchas consideradas como «irrelevantes», que tienen expresiones en la música, el arte, el baile y la cultura popular, que adoptan de la memoria colectiva los mitos, los vínculos sagrados con la naturaleza, los dioses y otras concepciones de la vida, etc. En comparación con estas, se encuentran aquellas expresiones mediáticas a gran escala que dominan la producción bibliográfica e irrumpen con mayor rigor en los espacios públicos de las grandes ciudades; como parte de sus estrategias de movilización, se proponen la toma reiterada de edificios gubernamentales, el bloqueo de avenidas principales, el enfrentamiento directo con la Policía, entre otros.

A partir de este planteamiento inicial surgen algunas interrogantes que son eje transversal de la discusión planteada en este artículo: ¿Cómo abordar luchas que tienen expresiones en los imaginarios populares y la memoria colectiva? ¿Es posible la comprensión de estas luchas bajo los marcos analíticos de la acción colectiva y los movimientos sociales? ¿Resulta acaso relevante documentar y visibilizar estas luchas bajo las 
miradas analíticas predominantes? ¿En qué términos puede justificarse esta relación? Si no es así, ¿bajo qué otras miradas es posible la interpretación? ¿Qué otras propuestas teórico-metodológicas resultan útiles para comprender las luchas que buscan recuperar y apropiarse del pasado?

Nuestro supuesto es que las luchas con expresiones en los imaginarios populares y la memoria colectiva están negadas en los rasgos visibles e inmediatos de la acción colectiva y los movimientos sociales que responden más bien a programas racionales y jerárquicos. Lo anterior es motivado también por el sensacionalismo de los medios de comunicación que redimensionan algunos conflictos al mismo tiempo que ocultan otras luchas, menospreciadas en la anécdota y la contingencia de una coyuntura particular. Al respecto, Holloway (2005) señala: «Distintas expresiones se expulsan o a un campo irracional, si las juzgamos desde la racionalidad dominante, o a un terreno prepolítico, si las juzgamos desde la doctrina revolucionaria del pasado por su debilidad organizativa e ideológica» (p. 83).

El objetivo de este artículo es desarrollar una propuesta teórico-metodológica que posibilite la comprensión de aquellas luchas con expresiones en la música, el baile, la cultura popular y la memoria colectiva, ancladas en la experiencia histórica local de Oaxaca, entidad del sureste mexicano. Así mismo, esta propuesta debe facilitar la recuperación de los rasgos y cualidades que han sido negados en los marcos analíticos predominantes de la acción colectiva y los movimientos sociales que terminan por descontextualizar y simplificar la complejidad que existe detrás de estas luchas que buscan la recuperación y apropiación del pasado.

Para lograr el objetivo propuesto, es necesario hacer una revisión de la pertinencia de los marcos de análisis de la acción colectiva y los movimientos sociales que están reduciendo las luchas a simples técnicas o herramientas para lograr cumplir objetivos específicos, particularmente en la política institucional. El fundamento de esta revisión gira en torno a la noción de Estado, considerado frecuentemente como una entidad 
externa y autónoma en la cual los diversos actores han concentrado sus esfuerzos de lucha para lograr una transformación social proyectada en el porvenir. El problema es que, al imaginar y construir esta sociedad futura a través de este esquema argumental Estado-céntrico, se niegan las posibilidades de recuperación y apropiación del pasado como formas de antagonismo social, debido a que las luchas son reducidas a instrumentos en los que permea una estrategia del olvido, sobre todo en el ámbito urbano.

Contraria a esta noción instrumental-pragmática presente en los marcos analíticos de la acción colectiva y los movimientos sociales, la propuesta teórico-metodológica que pretende este artículo retoma el concepto de lucha inserto en la tradición del marxismo abierto, particularmente en autores como John Holloway, Raquel Gutiérrez y Manuel Garza $(2016)^{1}$. Para Gutiérrez (2015), la lucha «(..) es la manera en la que el antagonismo social, de manera polimorfa, se despliega en el cuerpo social, exhibiendo su calidad desgarrada y presentando sus heterogéneos anhelos de transformación» (p. 19). Desde esta propuesta, el Estado ya no es el punto de partida para lograr el cambio social, sino que se concibe como una «forma» de las relaciones sociales capitalistas y, por lo tanto, atravesado por sus mismas contradicciones. «En realidad, lo que el Estado hace está limitado y condicionado por el hecho de que existe solo como un nodo en una red de relaciones sociales. Esta red de relaciones sociales se centra, de manera crucial, en la forma en la que el trabajo está organizado» (Holloway, 2005, p. 17).

Para sustentar estos argumentos, vamos a retomar la experiencia concreta de los integrantes de la Casa Autónoma Solidaria Oaxaqueña de Trabajo Autogestivo (Casota) que participaron durante los procesos

1 La tradición del marxismo crítico recupera posturas teóricas desarrolladas particularmente por Theodor Adorno, Max Horckeimer y Walter Benjamin en la llamada Escuela de Frankfurt. En México, esta tradición de pensamiento se cultiva actualmente en el Instituto de Ciencias Sociales y Humanidades de la Benemérita Universidad Autónoma de Puebla. 
de carácter político que se vivieron en Oaxaca a partir del año 2006. La experiencia de estos actores, así como otras expresiones de organización en Oaxaca, han sido poco visibles, poco documentadas, y se han considerado irrelevantes dentro de los acontecimientos mediáticos y espectaculares de la acción colectiva. Lo anterior se debe a que estas luchas se fueron desplegando a través del arte, la música, el baile y la cultura popular, inspiradas también en vínculos sagrados con la naturaleza, los mitos y los antepasados, entre otros, arraigados en las formas de vida de las comunidades indígenas que fueron (y siguen) imprimiendo sentido a los despliegues de los movimientos que irrumpen en la ciudad-capital.

Los hallazgos a nivel empírico de estas luchas nos demuestran que los marcos analíticos predominantes han quedado desbordados a partir de los acontecimientos del año 2006. Estos actores concretos no se expresaron bajo la gramática, las prácticas o los ritmos de la política estatal; no plantearon demandas al Estado y tampoco se organizaron a través de partidos y organizaciones sociales fuertemente estructuradas. Sin embargo, desde las coordenadas analíticas de los movimientos sociales, estas formas de lucha en la ciudad de Oaxaca, con su carácter festivo o artístico, se fueron reduciendo a la anécdota, en la cual los imaginarios y la memoria colectiva siguen resultando tan solo la «novedad» del movimiento social oaxaqueño. Al respecto, Garza (2017) indica:

Esos rasgos, que se consideran como «novedades» que de tanto en tanto aparecen en las expresiones de los movimientos sociales, constituyen precisamente un desbordamiento de la «forma» movimiento social. Es decir, la expresión de la lucha de los sujetos en contra de ser sometidos a la «forma», que reduce el antagonismo a mero conflicto (p. 30).

La discusión de este artículo se expone en cinco apartados, acompañados de uno adicional con conclusiones finales. El primer apartado tiene como objetivo profundizar en la evidencia empírica de los integrantes de la Casota y adentrarnos en la problemática de análisis. En el 
apartado siguiente se analiza la pertinencia de los marcos de interpretación que predominan en el estudio de la acción colectiva y los movimientos sociales para comprender esta experiencia organizativa que surgió en la ciudad de Oaxaca de Juárez. En un tercer apartado se exponen brevemente las inconsistencias que demuestran que los actores y sus subjetividades están invisibilizados dentro de los enfoques científicos. El cuarto apartado coloca como fundamento teórico-metodológico el concepto de «lucha» como expresión del antagonismo de relaciones sociales capitalistas. Por último, con esta propuesta teórica-metodológica, se hace una interpretación de las luchas desplegadas en Oaxaca y del papel que tienen los imaginarios y la memoria colectiva anclados en la experiencia histórica local como resortes que nutren el antagonismo constitutivo de una sociedad capitalista, más allá de concepciones instrumentales y pragmáticas.

\section{La construcción de la problemática}

Los acontecimientos de carácter político que se vivieron en la ciudad de Oaxaca a partir del año 2006 marcaron vidas de mujeres y hombres en circunstancias distintas y politizaron sectores de jóvenes con poca experiencia en el activismo, sin militancia activa en alguna organización social o partido político ${ }^{2}$. Después de aquel 14 de junio, estos actores se vincularon con antiguas tradiciones de lucha a través del levantamiento y defensa de las barricadas en sus barrios y colonias cercanas a la ciudad-capital, la ocupación de medios de comunicación locales (Zires, 2008) y la producción artística (Lache, 2008; Nahón, 2017), entre otros, a fin de recuperar al mismo tiempo imaginarios populares y creencias de la vida local ${ }^{3}$.

2 Este carácter político no hace referencia a la asimilación de la política con lo estatal. Para Rhina Roux (2005), lo político es un concepto que desborda lo estatal y se trata de una cualidad humana orientada a cuestionar y construir normas que regulan formas de convivencia común.

3 El día 14 de junio de 2006, la Policía Estatal recibió la orden del entonces gobernador de Oaxaca de desalojar el plantón de los maestros en el Zócalo, la Alameda y 
Sin embargo, la producción bibliográfica —que no ha sido menor durante este periodo - se ha reducido al plano descriptivo y a la crónica de los acontecimientos, como alusión a recortes de fotos periodísticas de primera plana o al monitoreo de acciones que irrumpen de forma espectacular en las calles. Algunos esfuerzos académicos y no académicos se han centrado en la comprensión de las expresiones colectivas de lucha desde sus grandes coordenadas o desde la visión de quienes las dirigen, vinculados a una estructura central de organización en la cual se establecen objetivos y se formulan demandas específicas ${ }^{4}$. Como parte de estos esfuerzos académicos y no académicos, los actores concretos han desaparecido prácticamente del campo de observación, al tiempo que los despliegues de las luchas han quedado en lo anecdótico y atrapadas en la contingencia, negadas en formas espectaculares de la confrontación abierta.

De esta manera, las expresiones de lucha que se sustentan en formas de socialidad comunitaria, mitos e imaginarios populares, han sido todavía poco visibles y documentadas. Durante los años 2006 y 2010, en el ámbito urbano fue posible observar que, en torno a estas dinámicas de organización contenidas en formas de la vida de los pueblos indígenas, se fueron organizando espacios de trabajo en distintos puntos de la ciudad-capital, así como en colonias y barrios cercanos, con la iniciativa

algunas calles aledañas de la capital. Los hechos se registraron en la madrugada, cuando la policía ocupó la plaza durante algunas horas; pero los maestros se reagruparon y volvieron para obligar a los cuerpos policiacos a replegarse. La acción de la policía resultó fallida, lo que originó el surgimiento de la APPO en un conflicto que se extendió hasta finales de noviembre del 2006, cuando la Policía Federal Preventiva (PFP) se presentó en la ciudad, tomó el centro histórico y desalojó a los integrantes de la APPO y a las diversas organizaciones que ahí se encontraban.

4 Particularmente, destacan obras como: Autoritarismo, movimiento popular y crisis política: Oaxaca 2006, de Víctor Raúl Martínez (2007); Oaxaca sitiada: La primera insurrección del siglo XXI, de Diego Osorno (2007), que constituye una crónica del movimiento; Oaxaca: insurgencia civil y terrorismo de estado, de José Sotelo (2008), que analiza los antecedentes que llevaron a la crisis del 2006; y Memorial de agravios, Oaxaca, México 2006, patrocinada por Rubén Leyva (2006). 
de aquellos jóvenes que no habían participado activamente en ninguna organización formal ni habían militado en partido político alguno.

Una de estas experiencias es «Voces Oaxaqueñas Construyendo la Autonomía y la Libertad» (Vocal), que surge en el año 2007 como un colectivo de jóvenes, en su mayor parte provenientes de las colonias de la ciudad de Oaxaca, cuyas expresiones se distanciaron de la actividad partidista-electoral; ellos buscaron generar un espacio para la autonomía y la autodeterminación en apoyo a las comunidades indígenas de Oaxaca. Durante el periodo de 2007 a 2008, la participación de estos jóvenes fue muy activa y surgió la propuesta de crear un espacio físico que se adhirió a la Casota, ubicada en una de las calles del centro histórico de la ciudad de Oaxaca, en donde fueron encontrando distintos actores de lucha.

En un inicio, la Casota no era un proyecto político, sino más bien una vivienda que en el transcurso de los meses se convirtió en un espacio de encuentro de los integrantes de diversos colectivos oaxaqueños como Espacio Zapata de la Asamblea de Artistas Revolucionarios de Oaxaca (Asaro), el Colectivo Hormigas Libertarias, el Proyecto Cultural «Demetrio Vallejo», el colectivo Autonomía, Autogestión y Autodeterminación (AAA) y los demás jóvenes de las colonias populares que participaban activamente en las barricadas y en las expresiones artísticas, entre otros.

Los integrantes de la Casota buscaron estrategias para acondicionar este lugar en el que tenían que hacer el pago de una renta mensual y brindar mantenimiento solidario a las instalaciones ocupadas para expresarse a través de la música, el arte, el baile, etc., que fueron adoptando de la memoria colectiva y los imaginarios populares anclados en la experiencia histórica local. El lugar era amplio, lo que permitió el desarrollo de expresiones diversas en las que cada pequeño rincón del espacio era útil para eventos musicales, conferencias y exposiciones artísticas-culturales. Asimismo, se discutían distintas temáticas 
relacionadas con los hechos ocurridos en el año 2006 como las violaciones a los Derechos Humanos, los presos políticos, la represión policiaca y la violencia desmedida del gobierno estatal y federal.

Cada rincón tenía asignado algún nombre relacionado con una fecha importante, personajes históricos o nombres de activistas asesinados. De esta forma, la Casota estaba compuesta por el dormitorio comunitario «14 de junio ${ }^{5}$ », la biblioteca «Ricardo Flores Magón», el comedor solidario, el patio central «2 de noviembre», el taller de serigrafía «25 de noviembre ${ }^{6}$ » y una tienda solidaria llamada «Lorenzo San Pablo Cervantes», en homenaje a uno de los activistas asesinados en el 2006 por grupos armados ${ }^{7}$.

A partir de estos planteamientos, se intenta problematizar el hecho de que estas experiencias colectivas de lucha han resultado poco analizadas en sus complejidades y contradicciones durante los acontecimientos que irrumpieron a partir del año 2006 en Oaxaca. La experiencia de los integrantes de estas expresiones de organización ha sido escasamente visibilizada y poco documentada, pues se ha considerado «irrelevante» debido al carácter efímero adquirido en el transcurso de los meses siguientes. Cabe mencionar que en el año 2011 resultó imposible para sus integrantes seguir sosteniendo el espacio rentado de la Casota, pues

5 Este día la Policía estatal recibió la orden del entonces gobernador de Oaxaca de desalojar el plantón de los maestros en el Zócalo y las calles aledañas de la capital. Los hechos se registraron en la madrugada, cuando la policía ocupó la plaza durante horas, pero los maestros se reagruparon y volvieron para obligarlos a replegarse. La acción resultó fallida y originó a la APPO.

6 El día 25 de noviembre de 2006 es una de las fechas más recordadas debido al enfrentamiento entre la APPO y la Policía Federal Preventiva, que dejó varias personas heridas, detenidos, desaparecidos y numerosos inmuebles y autos incendiados en la ciudad de Oaxaca de Juárez.

7 Lorenzo San Pablo Cervantes fue asesinado el día 22 de agosto de 2006 frente a las instalaciones de la estación de radio La Ley, por un grupo de policías sin uniforme que lo acribillaron. A doce años de este asesinato, sus familiares exigen justicia a partir de actos políticos-culturales en la ciudad de Oaxaca de Juárez (Nolasco y Jiménez, 2018). 
ya no pudieron continuar pagando el monto mensual de la vivienda. A raíz de esta situación, los diversos actores que participaban terminaron por fragmentarse, mientras que otras experiencias colectivas lograron mantenerse activas ante la adversidad, como es el caso del Espacio Zapata de la Asaro o los integrantes del Proyecto Cultural «Demetrio Vallejo», gracias a su trabajo en una librería independiente en donde continuaron con sus actividades durante otros meses.

\section{Los diagnósticos de la derrota}

Para cumplir el objetivo de este artículo, el acápite inicia con una digresión que busca al mismo tiempo brindar respuestas a algunas interrogantes planteadas inicialmente en este artículo. La digresión es la siguiente: en el análisis académico dedicado al estudio de los movimientos sociales y la acción colectiva, existen de antemano múltiples diagnósticos de la derrota en los que es posible monitorear algunas inconsistencias de perspectivas teórico-metodológicas. Desde una interpretación propia, estas nublan la comprensión de otras expresiones de lucha, debido a que las enmarca una noción instrumental que conduce a falacias reductivistas en el momento del análisis, como en el caso de las experiencias de los integrantes de la Casota, que se expresaron a partir de lo festivo y lo artístico, inspirados también en imaginarios y creencias populares.

Una primera noción de derrota hace referencia a la sensación que se percibe cuando al final de una gran movilización no se logran alcanzar los objetivos inicialmente trazados. Por ejemplo, la Asamblea Popular de los Pueblos de Oaxaca (APPO), que surgió a partir del fallido desalojo a los maestros del Zócalo de la ciudad-capital por parte de la Policía Estatal, tuvo como objetivo principal la salida del gobernador, pero en sus esfuerzos colectivos no se logró cumplir dicho propósito. ¿Fue entonces un fracaso el movimiento oaxaqueño al no alcanzar este objetivo? ¿Es posible comprender a los actores que se aglutinaron en torno a la 
APPO a partir de un objetivo visible y mediático como fue la exigencia de la renuncia de este personaje?

Al centrarse exclusivamente en este enfoque, resulta evidente que el movimiento social oaxaqueño fue derrotado debido a que el gobernador nunca dejó el cargo y terminó su periodo constitucional el día 30 de noviembre del año 2010. Sin embargo, el propósito de este argumento no es discutir aquí si el movimiento social oaxaqueño terminó derrotado o victorioso en ciertos aspectos. Lo verdaderamente importante son los rasgos y cualidades que están ocultos bajo este procedimiento metodológico que se utiliza para comprender las movilizaciones sociales y que está acompañado también de una noción particular acerca del Estado, concebido como un «objeto», una entidad externa que se piensa con relativa autonomía y al que van dirigidos los objetivos y demandas de grupos inconformes.

A partir de este planteamiento resulta evidente la comprensión de la derrota de los movimientos que han sido reducidos a instrumentos para lograr, bajo diversas estrategias, que esta entidad «externa» y «autónoma» pueda brindarles respuestas favorables a sus exigencias. Bajo esta perspectiva metodológica, se pueden observar desde expresiones de protesta legítima hasta la presencia de grupos de choque identificados con intereses caciquiles que deciden manifestarse de manera pacífica o buscar la confrontación directa en el espacio público como parte de sus estrategias de movilización. No obstante, estas acciones quedan reducidas a simples instrumentos en la medida en que están exigiendo al Estado el cumplimiento de alguna demanda puntual como ocurrió en el año 2006 en Oaxaca, con la demanda de renuncia del titular del ejecutivo local dirigida al Gobierno Federal. Desde esta mirada instrumental, las luchas se colocan entonces en una posición permanente de subordinación, aun cuando logran alcanzar los objetivos y demandas trazadas.

Las exigencias o demandas pueden ser formuladas de maneras muy diversas: mediante escritos, mediante manifestaciones públicas, cierres 
carreteros, ocupación de edificios, bloqueo de oficinas, huelgas. Pero, a pesar de los distintos grados de violencia que puedan implicar, no alteran la estructura fundamental de la relación: un grupo movilizado que demanda a una institución del Estado tomar una decisión en un sentido determinado. El grado de violencia puede variar, puede convertir una demanda en una exigencia, pero la posibilidad de tomar la decisión sigue en el mismo polo de la relación. (Garza, 2017, p. 26)

Así, tanto sindicatos, grupos y organizaciones sociales fuertemente estructuradas están caminando bajo esta perspectiva instrumental que está acompañada de una noción del Estado concebido como un «objeto» con existencia empírica a quien van dirigidos los objetivos y demandas planteadas por los distintos grupos inconformes. En Oaxaca, toman los espacios públicos los maestros y maestras disidentes, aglutinados en torno a la Sección XXII del Sindicato Nacional de Trabajadores de la Educación, que han planteado demandas a los gobiernos locales y nacionales en turno desde hace décadas; se movilizan también los concesionarios del transporte público y los taxistas que denuncian corrupción de funcionarios públicos, entre otros. Sin embargo, hay que insistir nuevamente en que el propósito de este argumento no es conocer qué tipo de movilización resulta más eficaz en Oaxaca para lograr respuestas favorables a sus objetivos y demandas; lo que es importante aquí son aquellos rasgos y cualidades que permanecen ocultos bajo esta aproximación predominante que nos lleva a considerar como «irrelevantes» otras experiencias de lucha colectiva, a las que se les atribuye, por lo tanto, una derrota anticipada.

Por ejemplo, se considera que, si la APPO como gran referente del movimiento social oaxaqueño en el año 2006, con su estructura y capacidad organizativa, no pudo alcanzar su objetivo principal (la salida del gobernador), existen menores posibilidades de conseguir algo a través de «pequeñas» acciones con expresiones basadas en la música, el arte, la cultura popular, que de manera evidente han ocupado un lugar relegado en los acontecimientos del año 2006 hasta la actualidad. Estos 
rasgos y cualidades ocultos son los que nos interesa mostrar aquí y para identificarlos es necesario exponer los procedimientos teórico-metodológicos que predominan en el análisis de las movilizaciones y que se acompañan de una noción particular del Estado, considerado como aquel lugar en donde hay que buscar una transformación social visible y permanente.

Cuando pensamos que las luchas son reducidas a instrumentos, lo que estamos apuntando también es que los marcos analíticos comparten el rasgo común de atribuir alguna forma de cambio que, además, es concebido como externo a los individuos; es decir, el cambio debe observarse allá «afuera»y, por lo tanto, es allá «afuera» en donde se debe orientar la lucha, con objetivos y demandas concretas, para resolver problemáticas sociales cuya resolución no está en nuestras manos sino en otra parte. En este sentido, la teoría de la movilización de recursos, como uno de los enfoques de los movimientos sociales, recupera algunos aspectos vinculados a la dimensión racional de los actores colectivos que dependen, sobre todo, de los recursos, la organización y las oportunidades para actuar en acciones colectivas. Para Tarrés (1992), «El proceso de movilización se conforma, por un lado, alrededor de individuos insatisfechos con un orden, que acumulan fuerza y desarrollan estrategias para incrementarlas; y, por otro, por actores que defienden el orden y manejan el control social porque son ellos quienes controlan los recursos que están en juego» (p. 745). En razón a esto, el éxito o fracaso de una movilización social, desde el enfoque de la teoría de la movilización de recursos, se puede detectar o identificar cuando los grupos movilizados han incrementado sus beneficios o son reconocidos como actores políticos por parte del aparato institucional.

La problemática de esto se hace evidente cuando aquellos objetivos y demandas no se alcanzan; lo que ocurre a partir de ahí, es que los despliegues de la lucha poco importan, porque lo importante entonces es volver a plantear otras estrategias, redefinir objetivos y emprender nuevamente la pugna a partir de cálculos racionales, sin equivocaciones o 
errores que puedan conducir a una nueva derrota. La lucha se convierte entonces en un objeto en el que no caben frivolidades debido a que el objetivo es «ganar»y los movimientos sociales se convierten en el instrumento que pueden permitir esa «victoria». Bajo esta mirada pragmática de las luchas, se anota entonces que allá «afuera» hay un sujeto con existencia empírica, una estructura de dominación que hace uso de una maquinaria que nos oprime de manera sistemática. La concepción que surge después es que, frente aquella maquinaria, casi indestructible, las luchas «pequeñas» con expresiones en los imaginarios populares, la música, el arte, el baile, la memoria colectiva, reducidas a simples herramientas y técnicas de protesta, son impotentes para destruirla, no funcionan, y se justifica así la irrelevancia de estas experiencias colectivas que están destinadas a la derrota.

Con este procedimiento instrumental ocurre una jerarquización de las luchas, una clasificación «objetiva» por la mayor o menor importancia que puedan adquirir, cuya medición se establece siempre a partir de las posibilidades que las acciones colectivas y los movimientos sociales tengan para alcanzar sus objetivos y demandas planteadas a aquella entidad «externa»y "autónoma», con mayor celeridad y garantía. El concepto de repertorio de confrontación en los movimientos sociales, utilizado por Tilly (2008), es una de las propuestas teóricas para analizar las formas de la acción colectiva a la que los movimientos recurren para alcanzar objetivos y generar cambios dirigidos al aparato estatal, modificar políticas o introducir cambios visibles y permanentes en la vida social a partir de la agenda pública.

Por este motivo, se piensa que, en lugar de que esos actores estén perdiendo su tiempo en ese tipo de acciones irrelevantes, lo que deben hacer es formular objetivos claros y una estructura y capacidad organizativa, material y económica, que posibiliten cambios reales, visibles y permanentes en aquel aparato de dominación; es decir, que generen la posibilidad de «victoria». Bajo estos términos, atribuir derrotas resulta entonces muy sencillo cuando se trata de luchas «pequeñas» en número de 
integrantes y escasos recursos materiales y económicos, como en el caso de los distintos procesos organizativos que se expresaron en los márgenes de la estructura formal de la APPO y que se manifestaron a través de acciones artísticas, musicales, inspiradas en imaginarios populares de la vida local de las comunidades indígenas de Oaxaca. Nasioka (2017) señala que, insistir en la tristeza de las luchas perdidas significa, finalmente, identificarse con la omnipotencia de los dominadores (p. 17).

En estos términos, Garza (2017) propende al cuestionamiento del concepto mismo de «movimiento social» que ha permanecido como marco analítico, pese a los cambios observables en los fenómenos empíricos. El autor expresa que la noción misma de «movimiento social» es un modo de existencia en el que se exterioriza y niega la lucha. «El concepto "movimientos sociales” fetichiza la lucha, en él desaparecen los sujetos en la acción creativa de resistir contra la negación de su propia humanidad. $\mathrm{Su}$ sentido se encuentra fuera de ellas, precisamente como objetivo a lograr» (p. 29). Raquel Gutiérrez (2015) apunta que, si bien el concepto de «movimiento social» permitió reinstalar la idea de lucha como central para la comprensión de los sucesos políticos e históricos, de inmediato sintió la tentación de clausurar la fuerza expresiva del término, que colapsa en un concepto cerrado: «El peligro principal de esta clausura conceptual es que vuelve a expulsar la lucha como clave para la intelección del asunto social, colocándola en un lugar secundario» (p. 16).

Hasta aquí, podemos señalar que esta digresión inicial acerca de la derrota de la acción colectiva y los movimientos no resulta vacía; contribuye a la identificación de algunas razones y rasgos ocultos que nos permiten explicar el poco trabajo documental que existe acerca de las experiencias organizativas de algunos activistas en Oaxaca como en el caso de los integrantes de la Casota. Los rasgos y cualidades que quedan ocultos a partir de estos marcos analíticos nos llevan también a la incomprensión de los despliegues de las luchas mismas dentro de estas experiencias organizativas en las que sus integrantes no buscaron el planteamiento de objetivos al Estado, no se expresaron bajo la gramática 
o ritmos de la política estatal y tampoco se organizaron a través de partidos y organizaciones fuertemente estructuradas para expresarse.

\section{La invisibilidad de los actores y la memoria colectiva}

El propósito no es visibilizar aquellas luchas que han sido poco documentadas, para documentarlas y visibilizarlas ahora a profundidad bajo los mismos procedimientos y enfoques instrumentales predominantes de la acción colectiva y los movimientos sociales. En Oaxaca son múltiples las expresiones de descontento que irrumpen de formas dispersas y no están concentrando sus esfuerzos en el planteamiento de objetivos y demandas puntuales dirigidos a aquella entidad «externa»; asimismo, tampoco reducen sus expresiones de lucha a herramientas o técnicas para alcanzarlos. El análisis de aquellas luchas que se expresan a partir de la memoria colectiva y los imaginarios populares no tiene ningún sentido si queda atrapado en estos términos instrumentales y pragmáticos de la acción colectiva.

Sin embargo, para la comprensión de estas luchas hay que ir más allá de la inmediatez de una coyuntura particular, como ocurrió con los acontecimientos del año 2006 en Oaxaca, cuando surgieron acciones multitudinarias y mediáticas en el espacio público. La memoria colectiva, los imaginarios y las creencias populares que buscan la apropiación del pasado no son procesos observables o medibles a primera vista en las distintas luchas desplegadas durante este periodo; por lo tanto, han resultado inaprensibles desde la observación empírica e irrelevantes desde las miradas instrumentales-pragmáticas que buscan el estallido de grandes conflagraciones amplificadas en el espacio público.

Lo anterior puede exponerse rápidamente si pensamos en la experiencia concreta de las barricadas que se construyeron y defendieron en la ciudad de Oaxaca y las colonias durante las movilizaciones del 2006, que han sido enmarcadas en una dimensión meramente instrumental de análisis que apunta a la autodefensa; es decir, las barricadas se han 
reducido a herramientas con el objetivo último de detener el paso de las camionetas de las denominadas caravanas de la muerte en aquellos agitados meses del año $2006^{8}$. La mirada enfocada en lo puramente espectacular y empíricamente observable deja de lado otros procesos y despliegues de las luchas, de los cuales se habla muy poco. Lo que no se puede observar en una lucha y, por lo tanto, lo que no se puede nombrar resulta incomprensible desde cualquier concepción instrumental de análisis académico y no académico. ¿Cuáles son esos rasgos y cualidades ocultos en las barricadas? La respuesta es la lucha misma que se desplegó en la construcción de esas barricadas, mediante la cual se recuperó la actividad creativa, la solidaridad entre amigos, vecinos, familiares, a través de historias, memorias e imaginarios populares, cuyos despliegues han quedado en el olvido, en tanto que estas luchas no responden a objetivos instrumentales que se deben alcanzar en algún lugar, allá «afuera», como es el caso del Estado.

Lo mismo ocurre cuando recuperamos experiencias organizativas como la Casota que empíricamente se materializó en una vivienda al norte de la ciudad de Oaxaca en el año 2008. Los despliegues de la lucha que hicieron posible esta experiencia colectiva y que se pueden identificar a través de «equivocaciones», «errores», encuentros y desencuentros de sus integrantes, resultan irrelevantes desde una noción instrumental que reduce estas luchas a herramientas para lograr objetivos cuya resolución ni siquiera está en manos de los propios actores sino en alguien más.

Los despliegues de las luchas están ocultos bajo estos procedimientos y es necesario continuar trazando coordenadas previas para exponer la dificultad que implica situarnos en una ruta teórico-metodológica que nos permita su reconocimiento y comprensión, más allá de los enfoques predominantes. Esta dificultad tiene que ver no solo con la

8 Se les denominó popularmente «caravanas de la muerte» a los grupos de vehículos que recorrían las calles de la ciudad, en los cuales viajaban policías de diversas corporaciones locales vestidos de civil, que disparaban en contra de los manifestantes. 
reducción de las acciones colectivas a una condición de instrumentos utilizados para alcanzar objetivos (como ya se discutió), sino también con una mirada particular de análisis científico que reduce las acciones a unidades de análisis visibles. La observación empírica es el punto de partida para analizar las acciones colectivas, identificarlas, clasificarlas, recortarlas y unir las partes que la integran en una realidad social que resulte visible y externa.

A partir de las acciones empíricamente visibles en los acontecimientos del año 2006, se ha ido recortando paulatinamente al movimiento oaxaqueño al cual, reducido a una herramienta y unidad de análisis, se ha buscado analizar de manera externa como un «objeto» integrado por distintas piezas recortadas. Para su comprensión, se retoma primero el surgimiento (causas) y después el momento de su «conclusión»o el momento posterior (consecuencias) con el objetivo de procurar la comparación entre cada una de estas piezas y hacer un balance de los resultados y objetivos alcanzados. Bajo estos procedimientos se está mirando hacia afuera de las luchas y no en los despliegues de las luchas mismas, señala Garza (2016); por lo tanto, el momento mismo de la lucha se convierte en algo vacío. Ante la pregunta, ¿tienen las luchas límites temporales?, el autor responde:

La pregunta por las consecuencias de la lucha está fundada en el supuesto de la discontinuidad que se establece en su interior. Se trata de rupturas que señalarían la diferencia entre momentos distintos: por una parte, entre el momento del surgimiento de la lucha y el periodo anterior a ella y, por otra parte, entre el momento de su conclusión y el periodo posterior. Esa separación sugiere que tanto el periodo previo al surgimiento de la lucha como el posterior a su conclusión serían diferentes al periodo temporal comprendido entre ambos momentos, es decir, el periodo de la lucha misma. La diferencia radicaría precisamente en la presencia -o ausencia- de él. (p. 212) 
Bajo esta concepción, surgen otras preguntas: ¿Dónde están los sujetos de las luchas? ¿Dónde quedan las subjetividades que se constituyen en las experiencias colectivas? ¿Cuáles son las ideas de justicia e injusticia de los actores movilizados? ¿Cuáles son sus agravios? ¿De dónde se nutren? Desde luego, no es el propósito aquí responder directamente estas interrogantes, sino, más bien, considerarlas como referencia inmediata ante la idea de que los actores concretos de las luchas desaparecen del campo de observación bajo los enfoques instrumentales y positivistas del análisis científico. Pero ¿acaso no fueron mujeres, estudiantes, campesinos, maestros, maestras, normalistas, indígenas, médicos, etc., quienes se movilizaron durante el año 2006 en Oaxaca? Entonces, ipor qué, desaparecen del campo de observación?

A partir de lo empíricamente observable en el espacio público, la tradición científica-positivista busca, primero, identificar a los actores que participan en las experiencias colectivas y, posteriormente, analizar la manera en que dichos actores fueron luchando. Las identidades quedan definidas de antemano y esto nos lleva a diferenciar entre luchas estudiantiles, feministas, indígenas, etc., cuyas clasificaciones están vinculadas al tipo de objetivos y demandas planteadas muchas veces desde los discursos unitarios de líderes que dirigen las luchas. Esto ha derivado en que el movimiento obrero, prototipo de la acción colectiva, haya tomado distancia debido a que, en las movilizaciones sociales convertidas en una "unidad de análisis», ya no es posible identificar situaciones de clase entre los actores movilizados. Por este motivo, se busca establecer otros criterios de clasificación con base al género, condición étnica, racial o tipo de demanda y objetivo, que permitan que las personas puedan tener la certeza de lo que ocurre en el espacio público.

Aquí hacemos referencia al enfoque de los nuevos movimientos sociales en autores como Melucci (2002), que consideran la existencia de nuevas formas de opresión y proponen la necesidad de otros criterios de clasificación de los actores, más allá de la situación de clase. En este sentido, en los meses del 2006 y 2007, en Oaxaca se buscó identificar 
y clasificar de manera mecánica a los actores que participaban en las marchas a través de conceptos cerrados; esas clasificaciones (maestros, estudiantes, indígenas) fueron desbordadas paulatinamente. La salida rápida ha sido definir al movimiento social oaxaqueño como popular ante una necesidad aparente de darle nombre a clasificaciones que eran evidentemente desbordadas en las luchas que fueron surgiendo en el transcurso de los meses siguientes.

En realidad, aun cuando los actores de las luchas hayan sido clasificados de manera anticipada, poco se conoce acerca de los actores concretos: sus frustraciones, sus miedos, sus concepciones de justicia, de opresión, sus sentimientos de agravios y humillaciones, entre ostros aspectos. El análisis científico-positivista e instrumental menosprecia todo aquello que no puede observar y, por lo tanto, aquello que no puede nombrar. Cuando las demandas no son claras, como ocurrió en los actos de confrontación directa, sencillamente se busca acusar a los grupos inconformes - que solo tiran palos y piedras- de «revoltosos».

Los actores concretos de las luchas han desaparecido prácticamente del campo de observación para aglutinarse en torno a discursos de líderes y organizaciones que niegan individualidades concretas a partir de la generalización de demandas y objetivos específicos. Sin embargo, esas frustraciones, miedos, sentimientos de justicia, opresión, humillaciones no figuran en los discursos unitarios de líderes y organizaciones sociales. De esta forma, los despliegues de la lucha misma poco importan, así como los actores concretos que las adelantan, ya que el objetivo principal está enfocado únicamente en buscar formas de cambio visibles en algún lugar de la estructura institucional. Ante el incumplimiento de esos objetivos, los despliegues de las luchas quedan en el simple registro anecdótico, debido a que permea una estrategia pragmática que tiene puesta la mirada siempre en el futuro inmediato, pues es en este tiempo particular cuando se puede saber si los objetivos y demandas han sido alcanzados. No interesa la recuperación y apropiación del pasado. 
Los despliegues mismos de la lucha contenidos en las actividades artísticas y festivas resultan entonces «irrelevantes» y quedan relegados al olvido. En razón a lo anterior, podemos comprender la creación de espacios como la Casota, que se convirtió en un espacio colectivo de encuentros y desencuentros entre amistades, vecinos y familiares con una participación activa de jóvenes de diversas experiencias organizativas artísticas como el Espacio Zapata, el Colectivo Hormigas Libertarias, el Proyecto Cultural «Demetrio Vallejo» y el colectivo Autonomía, Autogestión y Autodeterminación (AAA).

Por lo tanto, cuando se hace referencia a la Casota no se busca recortarla y tampoco se propone utilizar un modelo riguroso que faculte la identificación de las causas que la originaron. Si alguien nos pregunta aquí acerca del motivo principal del surgimiento de una experiencia como la Casota, la respuesta que podamos brindar poco importa. Tampoco importa dar cuenta de los efectos y los resultados obtenidos de manera directa o indirecta. En fin, no se trata de analizar un «objeto» para clasificarlo, recortarlo y luego unir la relación de sus partes de manera rigurosa, lo que en el fondo nos llevaría a jerarquizar las expresiones organizativas y también a dejar de lado los despliegues mismos de la lucha como aspectos centrales, tema que nos interesa discutir aquí.

Con base en estos argumentos, quedan por responder otras dos preguntas formuladas al inicio de este artículo: ¿Bajo qué otras miradas es posible la interpretación de estas luchas? ¿Qué otras propuestas teóricometodológicas resultan útiles para comprender las luchas que buscan recuperar y apropiarse del pasado?

\section{El concepto de «lucha» como antagonismo social}

Contraria a esta noción instrumental que conduce a la derrota de los movimientos sociales y, por lo tanto, a la de otras luchas consideradas pequeñas e irrelevantes, la propuesta teórico-metodológica que se retoma en este apartado recupera principalmente el concepto de «lucha» 
derivado de la tradición del marxismo abierto, que busca recuperar las categorías críticas de Marx (1986) para comprender el capital como una relación social. «La lucha para liberar el poder-hacer del poder-sobre, la lucha para liberar el hacer del trabajo enajenado, para liberar la subjetividad de su objetivación (...) La lucha para liberar el poder-hacer del poder-sobre es la lucha por la reafirmación del flujo social del hacer, contra su fragmentación y negación» (Holloway, 2005, p. 41).

En su libro Cambiar el mundo sin tomar el poder, John Holloway plantea como argumento central que, en la sociedad capitalista, «lo hecho es separado del hacer y se vuelve contra él. Esta separación de lo hecho respecto del hacer es el núcleo de una fractura múltiple de todos los aspectos de la vida» (p. 49). El núcleo central del análisis para analizar la «lucha» es la categoría hacer y el concepto de trabajo enajenado que Holloway utiliza en su propuesta para diferenciar entre trabajo concreto y trabajo abstracto; ambos conceptos resultan importantes para develar el significado profundo de las luchas como flujos continuos, intermitentes y contradictorios de antagonismos sociales.

La característica más importante y distintiva de las sociedades capitalistas, refiere Holloway, es que están mediadas por el intercambio mercantil como parte de esta fractura múltiple entre lo hecho respecto del hacer; por lo tanto, la forma histórica de su dominación no aparece como tal, porque no se desarrolla bajo la forma de relaciones de dependencia, ni por la coerción física directa, sino mediada por los intercambios de mercancías realizados entre individuos en apariencia libres e iguales. Para el autor, el capital es una relación social que hace referencia a una sujeción material, en la cual los individuos venden su fuerza de trabajo en el mercado debido a que han sido separados de su hacer; es decir, han sido separados no solo de los medios de producción necesarios para producir y reproducir materialmente su vida, sino que han sido separados también de su propia actividad humana. 
La dominación impersonal del capital no se reproduce, entonces, fuera de las luchas en contra de un enemigo empíricamente visible, sino a partir de nuestras propias relaciones sociales mediadas en el intercambio mercantil. No se trata de una maquinaria «externa», sino de relaciones sociales que nosotros en conjunto creamos y reproducimos de manera cotidiana en una sujeción material en la cual nuestra actividad humana (el hacer) está negada por el capital. La cuestión es que la negación del hacer está oculta debido a que las relaciones de dominación aparecen en la realidad en forma de objetos (trabajo abstracto). Marx (1986), en su obra El capital, señala que una peculiaridad de la sociedad capitalista es que las relaciones sociales aparecen no como lo que son (relaciones sociales de explotación), sino que asumen una forma fantástica de su realidad. Al retomar la crítica materialista a las categorías de la economía política, Marx refiere en esta obra que la dominación histórica del capital genera en la «superficie» relaciones sociales que son aprehendidas en la forma-dinero, el precio, la ganancia, etc., como parte esencial de la reproducción del capitalismo.

A la espera de que podamos discutir con mayor profundidad estos planteamientos teóricos en otro artículo, lo que se pretende mostrar por ahora es que las formas en que se exteriorizan las relaciones sociales, como parte de esa separación múltiple entre lo hecho y el hacer, no son nunca algo dado de antemano. «La forma-valor, la forma-dinero, la forma-capital, la forma-Estado, etcétera, no están establecidas de una vez y para siempre (...) Todo lo contrario, están constantemente en discusión, son constantemente cuestionadas como formas de relaciones sociales, son constantemente establecidas y re-establecidas (o no) por medio de la lucha» (Holloway, 2005, p. 95). Garza (2017) señala: «En cualquier ámbito, lo que es creación humana no solamente se aparece como algo independiente de su creador, sino que además lo niega. Pero negación no significa supresión; la actividad humana que crea objetos para el uso no desaparece en el trabajo capitalista, pues aquella actividad constituye su verdadero movimiento» (2017, p. 26). 
Por lo tanto, si la dominación del capital implica sometimiento de la actividad humana (el hacer), entonces, la emancipación solo puede significar liberación del poder-hacer; sin embargo, incluso al negar las relaciones sociales capitalistas, seguimos participando en su reproducción. Bolívar Echeverría (2000) expresa que lo peculiar no es que sobreviva el capitalismo. Si algo se debe tener claro, es que el capital sobrevive debido a que nosotros lo reproducimos cotidianamente. Entonces, lo peculiar no es que sobreviva el capital, sino que adentro del capitalismo hay otros modos de vida que están luchando, hay otras formas de existencia que están resistiendo; por lo tanto, la lucha contra el capitalismo no está «afuera», sino dentro del capital, como señala el autor en mención.

El poder-hacer existe en la forma de su propia negación como podersobre, señala Holloway (2005); es decir, la vida existe en el modo de ser negada; en esa medida, no desaparece, sino que existe como tensión antagónica con su propia forma de existencia, como poder-sobre. Por este motivo, la lucha contra la dominación del capital no puede plantearse objetivos específicos «afuera» de las luchas mismas, en un aparato estatal que aparece como una forma de estas relaciones capitalistas, sino que las posibilidades de liberación están ya contenidas en la existencia negada de la actividad humana (el hacer).

En su identidad interna, las luchas, como lucha en y contra el capital, son luchas contra la dominación pero que no puede manifestarse en su extrañeza frente a ella. Son, pues, parte de la propia imposición de la dominación. Solo pueden entenderse en su unidad con la dominación y en su mutua determinación, (...) la dominación no puede entenderse como una entidad exterior a la lucha que existe por sí misma como algo dado, sino que ella misma es lucha. (Garza, 2016, p. 101)

El Estado se convierte en una forma que adquieren las relaciones sociales capitalistas y por ninguna circunstancia resulta «externo» a una sociedad capitalista. Bajo esta argumentación teórico-metodológica, el Estado no puede ser el punto de partida para lograr la transformación 
de un orden social injusto en el que diversas movilizaciones en el espacio público han buscado, bajo múltiples estrategias pacíficas o violentas, intervenir y presionar para generar posibilidades de transformación en su estructura.

La tragedia constitutiva del capitalismo, señala Holloway (2005), es que su existencia depende del trabajo vivo, de la actividad del dominado y, por lo tanto, la emancipación solo puede significar liberación del poder-hacer a partir de la construcción de otros haceres que se expresan en la lucha misma y no en su «exterior». La lucha no significa participar en elecciones o en formular alguna demanda material-económica a una entidad aparentemente externa, como se ha reiterado, sino en la construcción de otras relaciones humanas que permitan la liberación del poder-hacer, la reapropiación del control de la vida. Para Garza y Sánchez (2017), «Ellas mismas [las luchas] son el propósito. Lo son porque constituyen la construcción en marcha de un mundo distinto de relaciones. Contradictorias, experimentales, defectuosas, insólitas, son luchas precisamente porque constituyen el despliegue de una negación concreta del mundo de la dominación» (p. 17). Situados en esta propuesta teórico-metodológica, podemos entender el sentido de las distintas expresiones de lucha como negación práctica de las formas de dominación del capital, que procuran de manera continua y contradictoria desarticular relaciones basadas en la explotación y la apropiación del trabajo vivo ante la valorización del valor.

\section{El estado del tiempo: la apropiación del pasado}

El Estado no es el punto de partida para lograr la transformación social, señala Holloway (2005), más bien, el Estado se concibe como una «forma» de las relaciones sociales capitalistas, atravesado por sus contradicciones. Existe una ruptura entre este planteamiento teóricometodológico y aquella sensación de derrota. Sin embargo, no basta con señalar que el Estado es una forma de las relaciones capitalistas con el objetivo de criticar aquella concepción cosificada del Estado y pensar, 
tal vez, que esa «forma» es producto de nuestra imaginación o un error interpretativo.

El Estado es muy real y despliega su violencia concentrada en sus instituciones, cuerpos policiacos, Ejército. En el año 2006, se desplegó en Oaxaca una violencia para perseguir y encarcelar líderes, activistas, maestros, entre otros; así mismo, la vía represiva se fortaleció en el año siguiente con detenidos, amenazados, asesinados y desaparecidos a tal punto que, a trece años de distancia, aún no hay justicia y los culpables siguen impunes. En los últimos días del año 2008, el espacio de la Casota fue centro de un ataque policiaco en el que fueron detenidos algunos de sus integrantes y la vivienda sufrió daños infraestructurales. Los distintos comunicados emitidos por estos activistas hacían referencia a la brutalidad y el abuso de la policía preventiva y municipal, que entraron a las instalaciones ubicadas en el centro de la ciudad.

De este modo, el Estado no es producto de nuestra imaginación o un error interpretativo, sino que los nudos problemáticos surgen más bien cuando pensamos que la lucha es un asunto de poder contra poder; es decir, una lucha frontal y abierta contra esa maquinaria que existe y despliega su violencia. Bajo esos términos, resulta efectivamente imposible que las «pequeñas» luchas puedan ser capaces de generar cambios o destruir aquella maquinaria como quedó demostrado en Oaxaca, en donde ni la APPO con su estructura organizativa pudo lograrlo. Holloway (2005) señala que la lucha para liberar el poder-hacer, para liberar la subjetividad de su objetivación, no es una lucha simétrica. Para el autor, el soporte material y la posibilidad de liberación de la dominación están ya contenidos en la propia dialéctica de la dominación del capital, es decir, en la existencia negada de la actividad humana (el poder-hacer).

Hay que insistir en que el argumento central de la propuesta teórica de Holloway es que en el capital «lo hecho es separado del hacer y se vuelve contra él. Esta separación de lo hecho respecto del hacer es el 
núcleo de una fractura múltiple de todos los aspectos de la vida» (p. 49). A partir de esta idea, se descubre el significado de las relaciones de dominación como negación de la actividad humana debido a que se rompe el flujo social del hacer. El poder-hacer existe entonces en la forma de su propia negación como poder-sobre; a saber, la vida existe en el modo de ser negada y por lo tanto no desaparece, sino que existe como tensión antagónica con su propia forma de existencia (poder-sobre). Por este motivo, la lucha contra la dominación del capital no puede plantearse objetivos específicos allá «afuera», dado que el Estado no es un sujeto «externo» a la sociedad capaz de actuar con voluntad propia, sino que su aparición es cosificada en un momento del despliegue mismo de la dominación de las relaciones capitalistas.

De esta manera, en la escalada de los despliegues de la lucha como antagonismo en Oaxaca, se buscó acondicionar la experiencia organizativa de la Casota con fechas históricas de los acontecimientos del año 2006, personajes históricos o nombres de activistas asesinados o desaparecidos por la represión sufrida en aquellos meses. La lucha en Oaxaca fue (y sigue siendo) en pro de recuperar y apropiarse del pasado frente a una estrategia del olvido, caracterizada por la capacidad de enterrar rápidamente a los muertos de las luchas, sobre todo, en el ámbito urbano. Esto se ha ido construyendo a partir de los lazos de solidaridad que se fueron creando después del 14 de junio de 2006. No importaba si estos actores eran hijos de maestros de la Sección XXII o jóvenes con alguna carrera universitaria en Bellas Artes, Sociología o alguna ingeniería, ni las condiciones socioeconómicas, profesionales, preferencias sexuales, etcétera.

Tampoco se buscaba establecer límites temporales de la experiencia de la Casota mediante los cuales se pudieran hacer balances de resultados cumplidos o no cumplidos; la lucha era (y sigue siendo) un flujo continuo para recuperar el poder-hacer. Raquel Gutiérrez (2015) apunta: 
El acercamiento a la lucha como clave central de comprensión no se concentra en la posibilidad de cierre del proceso de lucha y/o reorganización del cuerpo social a partir del reacomodo de los antagonismos que lo desgarran. Más bien, se asume el curso de las luchas como flujos continuos, aunque intermitentes de tales antagonismos desplegados. (p. 23)

Así, al considerar la lucha con un flujo constante, no existen límites temporales y tampoco se puede establecer con precisión si los actores están ganando o perdiendo, ya que la lucha como antagonismo social es un proceso que nunca acaba. Todo esto rompe con las nociones pragmáticas e instrumentales que constantemente pretenden establecer límites temporales en las luchas para determinar sus causas y consecuencias, al tiempo dejan sus despliegues en el vacío.

Esta lucha se expresa permanentemente entre la recuperación de la propia actividad humana (poder-hacer), subsumida y negada en los circuitos de la valorización de valor del capital, y la lucha del capital por subsumir y negar de manera más sofisticada, más sutil y profunda la actividad humana en las formas en que se nos aparece: la forma-valor, la forma-salario, la forma-dinero. Estos son eventos que siempre están ocurriendo, porque el antagonismo entre la relación del poder-hacer y el poder-sobre es un flujo constante de relaciones sociales en el que el poder-hacer consiste en recuperar aquello que otorga sentido a nuestras vidas. Pero la vida no es una cuestión abstracta, sino que está históricamente determinada y se desenvuelve en espacios y temporalidades determinadas, en donde las colectividades que ahí se encuentran se identifican con ellas mismas en sus modos de relacionarse y reproducirse.

Los despliegues de las luchas en la ciudad de Oaxaca por recuperar el poder-hacer se fueron nutriendo de formas de vida locales con entramados simbólicos propios, a partir de un sentimiento de comunidad que nos remite a aquello que los griegos entendían como koinoia politike, una asociación humana relativa a la política que expresaba la libertad del ser humano: el establecimiento de principios y reglas concernientes al 
«vivir juntos». En el libro primero de su obra La política, Aristóteles afirma que el hombre es, por naturaleza, un animal político y que la forma suprema de comunidad es la comunidad política entendida como vinculación entre individuos. Esta afirmación hace referencia a que las funciones compartidas con el mundo animal tenían un significado humano solo en comunidad política; es decir, en la construcción de un mundo normativamente ordenado: nociones compartidas de lo bueno y de lo malo, de lo justo y de lo injusto: «(...) la justicia es una cosa política o civil; porque no es otra cosa sino regla y orden de la compañía civil, y este juicio es la determinación de lo que es justo» (Aristóteles, s. f., p. 16).

Pero, más allá del pensamiento griego, la forma de comunidad puede rastrearse aquí en las sociedades antiguas de nuestra región, de América Latina y el Caribe, que han sido consideradas «tradicionales» y «atrasadas», porque reconfiguran a su paso vínculos sagrados con la naturaleza, los dioses, los antepasados y los descendientes. Dussel (1998) señala que, a lo largo de la historia, bajo distintas formas, han existido modos de ordenación de la convivencia humana, de unificación de los seres humanos en comunidad política, de formas de gobierno y administración de los asuntos públicos. Bajo sus respectivas diferencias y etapas históricas, podemos hacer mención de los grandes ordenamientos políticos de civilizaciones como la egipcia, la mesopotámica y, por supuesto, nuestra cultura mesoamericana sostenida, además, en mitos, leyendas, vínculos sagrados con la naturaleza, concepciones de la vida y la muerte.

En este sentido, estas otras formas de hacer que se desplegaron en la ciudad de Oaxaca no eran relaciones sociales ambiguas, no obedecían al hecho de no saber lo que se estaba construyendo durante esos meses en diversos espacios organizativos considerados procesos «irrelevantes». Los despliegues de la lucha como recuperación del control de la propia vida estaban sustentados en una noción de comunidad inspirada en los pueblos indígenas. Estas otras formas de hacer estaban enraizadas 
en la historia local con otras concepciones de la vida y la muerte, con imaginarios populares y mitos, entre otros, que hacen de la vida, no un horizonte abstracto, sino una existencia concreta asentada en un territorio y tiempo histórico. En este tiempo, la recuperación y apropiación del pasado y la memoria colectiva son aspectos constitutivos del antagonismo en una sociedad capitalista en la que el sentido de la vida está siendo constantemente negado. Para Dussel, la «vida humana (...) no es un concepto, una idea, ni un horizonte abstracto, sino el modo de realidad de cada ser humano en concreto, condición absoluta de la ética y exigencia de toda liberación» (p. 11).

\section{A modo de conclusión}

Si nosotros pensamos aquí la experiencia de la Casota a partir de los procedimientos instrumentales y «objetivos» de la acción colectiva y los movimientos sociales, tendríamos muy poco que aportar a los planteamientos teóricos ya expuestos en el transcurso de estos casi trece años acerca de los acontecimientos de Oaxaca. Es decir, a partir del año 2006 hasta la fecha, se ha publicado una cantidad extraordinaria de material bibliográfico que ha destacado las expresiones visibles y mediáticas de la politización de mujeres y hombres.

Estos esfuerzos académicos han centrado sus análisis en el estudio de objetivos y demandas particulares del movimiento social oaxaqueño, así como en las distintas estrategias adoptadas para alcanzarlos. Poco importan en realidad si estas eran pacíficas o radicalmente violentas, debido a que las luchas son reducidas a simples instrumentos, en los que la falta de respuestas favorables por parte del Estado provoca el escalamiento de conflictos a mayores proporciones en el espacio público. Desde esta mirada instrumental, existe un consenso generalizado del fracaso anticipado de las distintas experiencias organizativas que buscan la apropiación del pasado y la memoria colectiva, gracias a la impotencia que se les atribuye para alcanzar los objetivos propuestos por las grandes movilizaciones. 
Además, si nos enfocamos en los resultados de estas experiencias colectivas, estamos asumiendo que la lucha de estos actores ya no existe y, que la desintegración de experiencias colectivas como la Casota no es más que la culminación de un proceso que tuvo un principio y un final de derrota, al no lograr la permanencia de sus acciones colectivas en el escenario público. Por ejemplo, si pensamos que los integrantes de la Casota terminaron por separarse en el año 2011, vamos a señalar que esa fecha representa su conclusión y lo que siguió es la realización del balance de sus resultados. Con base en estos términos, no se podría pensar, incluso, que la lucha es un flujo continuo e intermitente que no se reduce a las acciones visibles y espectaculares que irrumpen en los espacios públicos.

Se establecen, entonces, luchas «más importantes» y luchas «menos importantes», cuya medición se establece casi siempre a partir de las posibilidades que las experiencias organizativas tengan para alcanzar objetivos en el futuro inmediato de manera eficiente. Contrario a estas concepciones instrumentales, interesa en este artículo identificar los despliegues de la lucha misma en experiencias organizativas como la Casota; si bien esta ha sido poco documentada y reducida a la anécdota, no se puede negar el antagonismo que existe como parte de una sociedad capitalista. El propósito no es entonces visibilizar esta experiencia colectiva concreta bajo los mismos procedimientos y enfoques instrumentales predominantes, sino, más bien, identificar en la escalada de los despliegues de las luchas de sus integrantes las imprudencias creadoras, los riesgos, las «torpezas» y las «equivocaciones» que juegan un papel inesperado, en tanto que no responden a programas racionales y jerárquicos.

En razón a esto, para comprender esta experiencia organizativa concreta, se buscó desarrollar el concepto de «lucha» como antagonismo social de las relaciones sociales capitalistas, en las cuales las formas de socialidad comunitaria contenidas en mundos de la vida indígena mitos e imaginarios populares relacionados con el tiempo, la relación 
vital con la tierra, el respeto sagrado a la naturaleza, etc. - están imprimiendo sentido a las luchas que adelantan estos actores en Oaxaca, en un proceso continuo e intermitente que sigue presente hasta nuestros días. Sin embargo, esto no puede comprenderse fácilmente en la sociedad moderna, occidental, que se concibe como fruto de un pensamiento científico-positivista y, por lo tanto, intenta definirse en contra de estos imaginarios populares que resultan «poco civilizados», «arcaicos», para el pensamiento científico-positivista, a los cuales la razón universal debe «iluminar» para superarlos.

Las ciencias empíricas que retoman las acciones empíricamente visibles en el espacio público parecen dar cuenta de una realidad racional, cuantificable, secular y objetiva que considera que las costumbres, la religiosidad, la espiritualidad de las comunidades indígenas son irracionales y no tienen ninguna relevancia en las movilizaciones que se despliegan en los centros urbanos. No obstante, estos imaginarios arraigados en la memoria colectiva y el pasado de los actores concretos están imprimiendo sentido a las luchas en Oaxaca como una forma de antagonismo social.

Poco importa si las materializaciones organizativas como la Casota y otras formas de organización colectiva a lo largo de los acontecimientos del año 2006 fueron destruidas o desmanteladas. Lo importantes es que, con esas materializaciones, no han desaparecido los aprendizajes y las experiencias que dieron lugar a su construcción, que permitieron construirlas y que se encuentran arraigados en la memoria y el pasado de los actores concretos. Sirva entonces este esfuerzo para reconocer y comprender la lucha de los vencidos del ayer y la voz de los olvidados de hoy, de los nadie y los ningunos, que no son, aunque sean - nos dijo en alguna ocasión el escritor Eduardo Galeano-; no para precisar la idea de una sociedad del "porvenir», sino para cambiar la mirada y buscar formas de vida dignas en las sociedades presentes que cultivan críticamente el pasado. 


\section{Bibliografía}

Aristóteles (s. f). La política. Pedro Simón Abril (traductor). Madrid: Ediciones nuestra raza. Recuperado de http://fama2.us.es/fde/ocr/2006/politicaAristoteles.pdf

Bloch, Ernst (2007). Principio esperanza, tomo I. Madrid: Editorial Trotta.

Dussel, Enrique (1998). Ética de la liberación en la edad de la globalización y de la exclusión. Madrid: Editorial Trotta. Recuperado de: https://enriquedussel.com/txt/Textos_Libros/50.Etica_de_la_liberacion.pdf

Echeverría, Bolívar (2000). La modernidad de lo barroco. México D. F.: Era.

Garza, Manuel (2017). En torno a la crítica del concepto de movimientos sociales: negación y lucha de clases. Persona y sociedad, 31(2), 12-34. Recuperado de: https://dialnet.unirioja.es/servlet/articulo? codigo $=6248685$

Garza, Manuel y Sánchez, Ever (2017). Reflexiones epistemológicas entorno al concepto de movimientos sociales: negación y construcción cotidiana de un mundo otro. Revista de Estudios Sociales, 60, 12-24. Recuperado de https://dx.doi.org/10.7440/res60.2017.01

Garza, Manuel (2016). Insurrección, fiesta y construcción de otro mundo en las luchas de la APPO. Oaxaca 2006-2010. México: Juan Pablos Editor.

Gutiérrez, Raquel (2015). Horizonte comunitario-popular: antagonismo y producción de lo común en América Latina. Bolivia: Editorial Autodeterminación.

Hinkelammert, Franz (2007). Hacia una crítica de la razón mítica. El laberinto de la modernidad. Materiales para la discusión. Costa Rica: Arlekín. Recuperado de: http://coleccion.uca.edu.sv/franz-hinkelammert/items/ show/2201

Holloway, John (2005). Cambiar el mundo sin tomar el poder. El significado de la revolución hoy. Venezuela: Vadell Hermanos Editores, C. A. Recuperado de: https://ilusionismosocial.org/pluginfile.php/601/mod_resource/content/3/cambiar-el-mundo-el-poder-1275850.pdf

Lache, Norma Patricia (2008). La calle es nuestra: intervenciones plásticas en el entorno de la Asamblea Popular de los Pueblos de Oaxaca. En: Víctor Martínez (coord.), La APPO: irebelión o movimiento social? (nuevas formas de expresión ante la crisis). México: Universidad Autónoma Benito Juárez de Oaxaca. 
Marx, Karl (1986). El capital. Crítica de la economía política. México: Fondo de Cultura Económica.

Melucci, Alberto (2002). Acción colectiva, vida cotidiana y democracia. México: Centro de Estudios Sociológicos.

Nahón, Abraham (2017). Imágenes en Oaxaca: arte, política y memoria. México: Cátedra Jorge Alonso. Recuperado de: http://www.catedraalonsociesas.udg.mx/sites/default/files/imagenesenoaxaca.pdf

Nasioka, Katerina (2017). Ciudades en insurrección. Oaxaca 2006/Atenas 2008. México: Cátedra Jorge Alonso. Recuperado de: http://www.catedraalonsociesas.udg.mx/sites/default/files/ciudadeseninsurreccion.pdf

Nolasco, Darío y Jiménez, Jesús (2018). Sección 22 y familiares de Lorenzo Sampablo exigen justicia a 12 años de su asesinato. ADN Noticias. Recuperado de: https://www.adnsureste.info/familiares-y-amigos-de-lorenzosampablo-exigen-justicia-a12-anos-de-su-asesinato-1150-h/

Roux, Rhina (2005). El príncipe mexicano: subalternidad, historia y Estado. México: Era.

Tarrés, María Luisa (1992). Perspectivas analíticas en la sociología de la acción colectiva. Revista Estudios Sociológicos, 30, 735-757. Recuperado de: http:// aleph.academica.mx/jspui/bitstream/56789/23970/1/10-030-1992-0735. pdf

Tilly, Chales (2008). Contentious performances. Nueva York: Cambridge University Press.

Vélez, Octavio (2006). Ataca la PFP tras marcha de la APPO; más de 100 heridos. La Jornada. Recuperado de: https://www.jornada.com.mx/2006/11/26/ index.php?section $=$ politica\&article $=003 \mathrm{n} 1 \mathrm{pol}$

Zires, Margarita (2008). Estrategias de comunicación y acción política. Movimiento social de la APPO-2006. En: Víctor Martínez (coord.), La APPO: ¿rebelión o movimiento social? (nuevas formas de expresión ante la crisis). México: Universidad Autónoma Benito Juárez de Oaxaca. 